\title{
Underwater peroral endoscopic myotomy
}

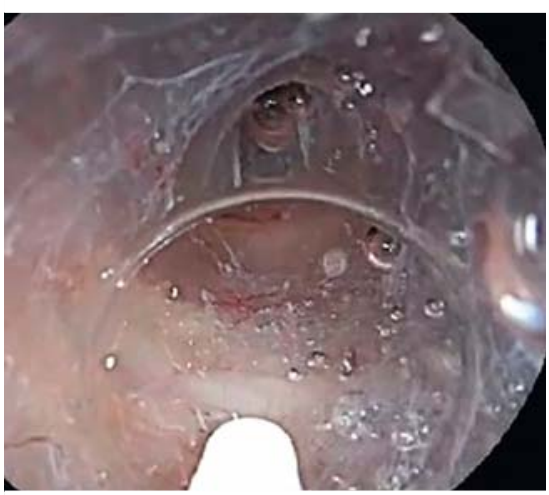

Dig. 1 Underwater peroral endoscopic myotomy.

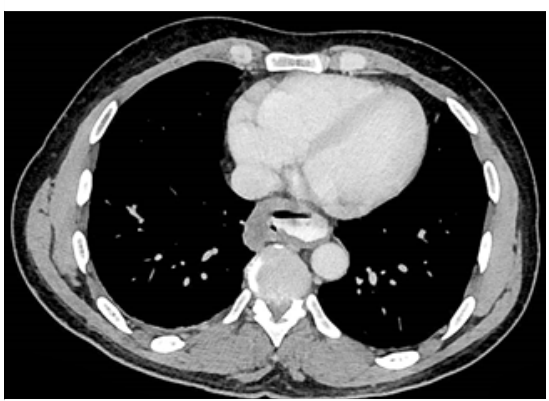

> Fig. 2 Thoraco-abdominal computed tomography with oral contrast intake performed on the first postoperative day.

Peroral endoscopic myotomy (POEM) is an accepted treatment modality for achalasia [1]. However, postoperative pain, mainly related to $\mathrm{CO}_{2}$ insufflation causing pneumothorax, pneumomediastinum, and pneumoperitoneum, occurs in $25 \%-85 \%$ of patients [2,3]. Underwater endoscopic resection is an emerging strategy for the management of duodenal and colorectal lesions [4]. We introduced underwater POEM with the aim of limiting the complications of $\mathrm{CO}_{2}$ insufflation.

A 53-year-old man was diagnosed with type II achalasia following the onset of solid food dysphagia, regurgitation, and weight loss. We decided to treat him with POEM.

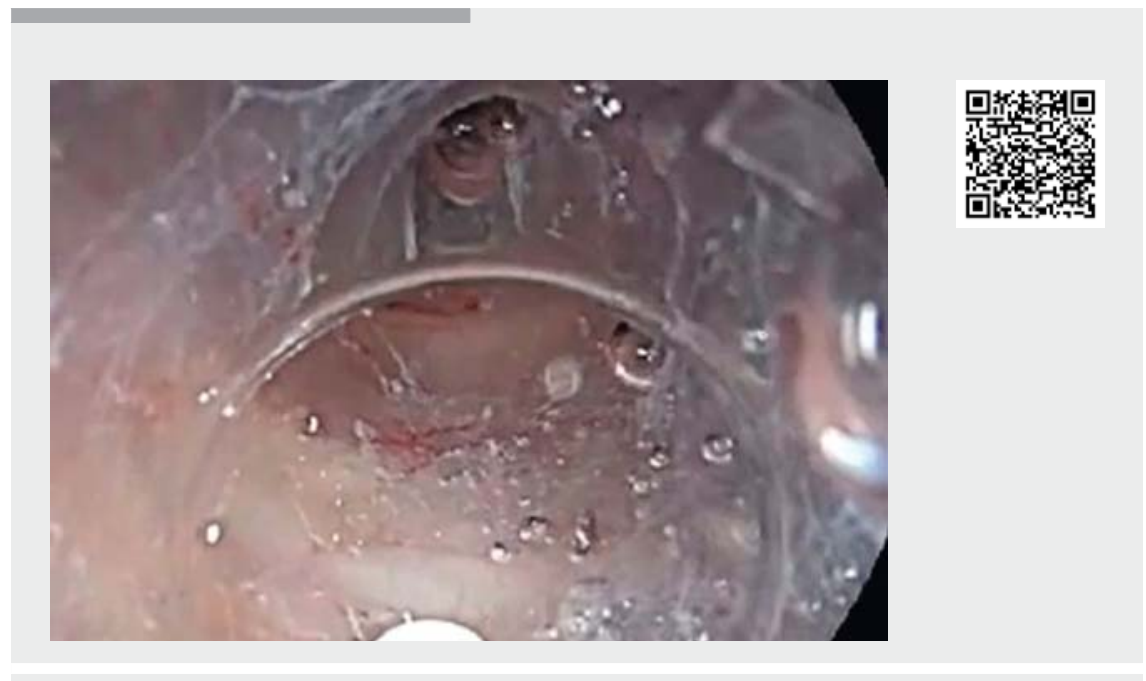

$\checkmark$ Video 1 Underwater peroral endoscopic myotomy.

The procedure was completed under general anesthesia with orotracheal intubation, using a cap attachment (ST Hood; Fujifilm, Tokyo, Japan), a Fujifilm 700 gastroscope, and a triangle-tip knife J (Olympus, Tokyo, Japan). After injecting the submucosa with indigo-stained saline and performing posterior transversal mucosal incision, we started submucosal tunneling in spray coagulation mode for $1 \mathrm{~cm}$. We then stopped $\mathrm{CO}_{2}$ insufflation and pumped sterile saline solution into the tunnel though the waterjet channel of the endoscope. Submucosal tunneling and myotomy were performed using the triangle-tip knife and the usual generator settings for spray coagulation (effect 4) and endocut (effect 1/3-3). The mucosal incision was closed with four 16-mm endoclips (> Fig. 1, > Video 1).

The postoperative course was unremarkable, and the patient was discharged after 24 hours. Thoraco-abdominal computed tomography with oral contrast intake performed on the first postoperative day ( $>$ Fig.2) showed a minimal pneumomediastinum without perforation, and absence of pneumoperitoneum or subcutaneous emphysema.
We have performed underwater POEM in three patients at our institution, with favorable outcomes. This technique is feasible and safe, offers optimal visibility during the procedure, and has the potential to limit insufflation-related complications.

Endoscopy_UCTN_Code_TTT_1AO_2A]

\section{Competing interests}

The authors declare that they have no conflict of interest.

\section{The authors}

\section{Rachel Hallit, Maximilien Barret, Einas} Abouali, Arthur Belle, Chloé Leandi, Romain Coriat, Stanislas Chaussade

Gastroenterology Department, Cochin University Hospital, Assistance Publique Hôpitaux de Paris and University of Paris, Paris, France 


\section{Rachel Hallit, MD}

Gastroenterology Department, Cochin University Hospital, Assistance Publique Hôpitaux de Paris and University of Paris, 27, rue du Faubourg St Jacques, 75014 Paris, France

Fax: +33-1-58411965

rachelhallit@hotmail.com

\section{References}

[1] Zihni AM, Dunst CM, Knowles T et al. Laparoscopic Heller myotomy vs per oral endoscopic myotomy (POEM): evolving criteria for achalasia treatment selection. Gastroenterology 2018; 154 (Suppl. 01): S-1271
[2] Pannu D, Yang D, Abbitt PL et al. Prospective evaluation of CT esophagram findings after peroral endoscopic myotomy. Gastrointest Endosc 2016; 84: 408-415

[3] Ren Z, Zhong Y, Zhou P et al. Perioperative management and treatment for complications during and after peroral endoscopic myotomy (POEM) for esophageal achalasia (EA) (data from 119 cases). Surg Endosc 2012; 26: 3267-3272

[4] Nett A, Binmoeller K. Underwater endoscopic mucosal resection. Gastrointest Endosc Clin N Am 2019; 29: 659-673

\section{Bibliography}

Endoscopy 2021; 53: 94-95

DOI 10.1055/a-1173-7953

ISSN 0013-726X

published online 29.5 .2020

(c) 2020. Thieme. All rights reserved.

Georg Thieme Verlag KG, Rüdigerstraße 14,

70469 Stuttgart, Germany

\section{ENDOSCOPY E-VIDEOS}

https://eref.thieme.de/e-videos

口回回 Endoscopy E-Videos is a free Fection, reporting 回舴: on interesting cases and new techniques in gastroenterological endoscopy. All papers include a high quality video and all contributions are freely accessible online.

This section has its own submission website at https://mc.manuscriptcentral.com/e-videos 